To appear in Chinese Economy, No. 6 (2012)

\title{
The Evolution of China's City Size Distribution: Empirical Evidence from 1949 to $2008{ }^{1}$
}

\author{
Zhenpo Wang, Professor \\ Tianjin Institute of Urban Construction \\ Tianjin, People's Republic of China (PRC) \\ Email: zhenpo@126.com \\ Jiangnan Zhu, Assistant Professor \\ Department of Political Science \\ University of Nevada, Reno \\ 1664 North Virginia St. \\ Reno, Nevada, U.S.A. 89557-0302 \\ Email: jzhu@unr.edu
}

\begin{abstract}
This paper studies the evolution of China's city size distribution, measured by nonagricultural population, from 1949 to 2008. We employ time series Gini coefficients, panel unit root test of Gibrat's law, and analysis of distribution dynamics, to check the robustness of our findings. We find that although China's city size distribution presented different patterns of growth in the short run, it has shown an approximately parallel growth model in the long run. This indicates that the parallel growth rule of city size distribution also applies to developing countries, though it might work differently there. In countries with relatively mature and complete urban systems, the parallel growth results from similar growth rates in all the cities. In developing countries experiencing rapid urbanization, the parallel growth mainly results from the emergence and rise of a large number of new cities, which offsets the fast growth rate of large cities. This also demonstrates that government policy aiming at affecting city size may be misleading.
\end{abstract}

Keywords: City Size Distribution, Gini Coefficient, Gibrat's Law, Dynamic, Urban Growth

\section{Introduction}

China has undergone a striking acceleration of urbanization along with the rapid economic growth. As Davis and Henderson (2003) point out, urbanization and economic development tend to go hand-in-hand, when a country moves "from a rural-agricultural base to an urban-industrial

\footnotetext{
${ }^{1}$ This research is financially supported by Chinese National Philosophy and Social Science Innovation Base (Guojia zhexue yu shehui kexue chuangxin jidi) for Regional Economy, a "985 Project" (Project No. 1052 122004700007). We thank Professor Shunfeng Song for valuable comments and Brandon T. Condren for helping editing the article. All mistakes and errors remain the authors' responsibility.
} 
To appear in Chinese Economy, No. 6 (2012)

base."2 Statistics shows that before the People's Republic of China (PRC) was founded in 1949, there were only 67 cities in China, including 9 in Taiwan. ${ }^{3}$ However, in the following 50 years, with upgrading of former counties and emerging of new cities, the total number of cities had reached to 667 in 1999. The urban population similarly jumped from 39 million in 1949 to 630 million by the end of 2010, while the share of urban population increased from a mere 7.3 per cent to 47 per cent. ${ }^{4}$ Moreover, by the end of 2008, there are 118 large cities with populations that exceed 1 million and 39 super-large cities with populations over 2 million. ${ }^{5}$

Chinese urban planners have made many urban development policies aiming at controlling and directing the development of city size in the past several decades in response to the rapid urbanization. ${ }^{6}$ At the same time, decision-makers also face dilemmas and debates on choosing from different city sizes for prior development. Many people believe in the leading role of large cities during urbanization and economic development. Large cities are thought to have more advantages of scale and agglomeration economies in industrialization, consumption and distribution, higher productivity, more job opportunities, and higher average income than smaller cities (e.g. Tiffen 2003; Zhou 2009). These advantages have partially motivated the 130 million rural workers on the move in China today pouring from villages to cities (Chang 2008). This, on the one hand, provides cities with a free flow of cheap labor; on the other hand, has led to a swelling of urban population in many large cities. Cities with overwhelming large scales could be hard to manage politically and economically. "Public services are usually unable to meet the

\footnotetext{
${ }^{2}$ Davis, J. C. and Henderson, J. V. (2003) Evidence on the political economy of the urbanization process, Journal of Urban Economics, 53, pp.98-125, p.98.

${ }^{3}$ Anderson, Gordon, and Ying Ge. "Do Economic Reforms Accelerate Urban Growth the Case of China " Urban Studies 41, no. 11 (2004): 2197-210, p.2199

${ }^{4}$ National Statistical Bureau, 2011.

${ }^{5}$ City Blue Book (chengshi lanpi shu) (Chinese Social Science Academy, 2009), http://news.xinhuanet.com/politics/200906/15/content_11545270.

${ }^{6}$ For recent policies on urban spatial growth, see Ding, Chengri, and Xingshuo Zhao, "Assessment of Urban Spatial-Growth Patterns in China during Rapid Urbanization." Chinese Economy 44, no. 1 (January-February 2011): 46-71.
} 
needs of the improving urban life due to insufficient urban infrastructure."7 Cities with a large population also place severe ecological stress on "both local human living conditions and on regional life-support ecosystem." ${ }^{8}$ Thus, the other group of policy-makers and scholars has advocated developing middle and small cities. They argue that middle and small cities are the main body of Chinese city system, and they spread more evenly around China geographically. These cities are also the backbone for socio-economic development in less-developed regions. ${ }^{9}$ However, an underlying question widely overlooked is how much government policies can affect city size distribution. To answer this question, a primary objective of this paper is to examine the long-term evolution of city size distribution in China from 1949 to 2006.

How would cities in a region or a country develop, grow, or expand? Theoretically speaking, there are only three possible models. The first is convergent growth, that is, many new cities emerge one after another, while small cities outpace and eventually catch up with the relatively large cities. Gradually the distribution of different-sized cities in the whole urban system tends to achieve balance. The second model is divergent growth, wherein large cities expand faster than smaller ones in the process of urbanization. Gradually city size distribution in the whole urban system becomes increasingly unbalanced. The last model is parallel growth, that is, cities of all different sizes grow with relatively same pace. Thus, the city size distribution remains stable over time. However, which model does China, a quickly growing and urbanizing country, follow? Most empirical studies of urban growth have focused on the experience of developed countries, especially the United States, and very little attention has been paid to developing countries. In

\footnotetext{
${ }^{7}$ Wang, Jianhong, Atushi Koizumi, and Xinrong Liu. "Advancing Sustainable Urban Development in China " Municipal Engineer 161, no. MEI (2008): 3-10, p.3.

${ }^{8}$ Wang, Rusong, and Yaping Ye. "Eco-City Development in China." Ambio 33, no. 6 (2004): 341-42, p.341.

9 "Gu Shengzu: Relying on townships develop middle and small cities to strengthen county-level economy" (Gu Shengzu: yixiancheng wei yituo fazhan zhongxiao chegnshi zhuangda xianyu jingji), source: Chinese Economic Net (zhongguo jingjiwang), March 6 2011,

http://www.ahagri.gov.cn/detail_zw.asp?newsid=33360\&typeid=17\&typename=\%CF\%D8\%D3\%F2\%BE\%AD\%BC\%C3
} 
To appear in Chinese Economy, No. 6 (2012)

this research, we also attempt to provide some insights on city size distribution in developing countries using evidence from China, while looking for policy implications from Chinese urban growth at the same time.

In the following, we first review existing literature on city size distribution in recent years. Scholars have found different patterns of Chinese city size distribution partially because they use data from different time periods or different regions in China. In other words, a systematic examination of the overall development of city size distribution across the whole of China and across different eras is needed. Therefore, we take four different samples of data from 1949 to 2008 to examine urban growth in China. In addition to the commonly employed time series Gini Coefficients, we also apply more advanced methods, such as the panel unit root test of Gibrat's Law and analysis of distribution dynamics, to analyze the over-time development of city size distribution and the correlation between initial city size and urban growth rates. We find that although China's city size distribution presented different patterns of growth in the short run, it has shown an approximately parallel growth model in the long run, especially since the 1990s. In the conclusion section, we give potential explanations to our major findings and discuss policy implications.

\section{Different Views on City Size Distribution in China}

Most empirical and cross-country studies show that city size distribution does not vary very much in the long-term. For instance, Madden (1956) examined the changing size distribution of American cities between 1790 and 1950. He found that although the scope and scale of the urban system had expanded very quickly and that city ranks had also changed in the hierarchy, the distribution model of different-sized cities had shown to be quite stable. Easton and Eckstein (1997) studied the population data of the top 40 cities in both France and Japan during the time 
To appear in Chinese Economy, No. 6 (2012)

period of 1876-1990, when both countries underwent industrialization and urbanization. They compared the Lorenz curves of city size distribution in different periods and found that the French urban system had displayed a significant pattern of parallel growth, where the average annual growth rate of urban population was unrelated to city scales. The Japanese urban system had presented an approximately parallel growth model with a slightly divergent growth, where the average annual growth rate of urban population was positively, but statistically insignificantly correlated with city scales. Black and Henderson (1999) constructed a theoretical model explaining the parallel growth of cities with a Markov chain. The development of the American city system of 1900-1990 supported their model. Sharma (2003) investigated the changing patterns of Indian urban system of 1901-1991 and found that the Indian city system showed a parallel growth in the long run with some deviations in the short run.

There is a long history of city development in China and many scholars have studied the changing size distribution of Chinese cities in the past several decades. Xu (1982), Sun (1984), and Zhou (1986) analyzed the hierarchical structure of China's city size distribution in the twentieth century until the 1980s. They found that Chinese large (i.e. urban population of 0.5-1 million), very-large (i.e. urban population of 1-2 million), and super-large cities (i.e. urban population above 2 million) had been rising both in terms of numbers and population proportion by the 1960s. These large cities' status within the whole urban system had been strengthened across time, while middle and small cities had become less important. However, from the 1960s to the 1970s, the status of large cities, especially very-large and super-large cities, started to decline within the city system, and middle cities grew the most quickly. When it came to the 1980s, while small cities greatly increased in numbers, large cities, especially very-large cities, regained their momentum of rapid growth again. In contrast, Wang (2000), utilizing an urban 
To appear in Chinese Economy, No. 6 (2012)

population data between 1984 and 1995 and based on the Pareto law and normal-Gini model, showed that middle and small cities grew more quickly than large cities in China. Song and Zhang (2002) applied the Pareto law on China's city size distribution with a sample of urban population data from 1991 to 1998 . They found that China's city size distribution became flatter during the 1990s, or "cities became more even in size." ${ }^{10}$ And Xu and Zhu (2008), using panel data of cities at prefectural and provincial level between 1990 and 2000, found that smaller cities grew faster than larger cities during this period in China. ${ }^{11}$

Hence, scholars have disagreed on the development of China's city size distribution. Moreover, most existing research has focused on the over-time changes in the size distribution of Chinese cities. Very little research has been conducted on the relation between the initial city size and urban growth rate. As the literature on developed countries shows, whether cities of different sizes have maintained a similar growth rate can also help explain the general trend of city size distribution. Guo et al. (2004) examined the changing patterns of city size distribution based on urban population data from 1984-2001 in two different areas, the economic zone surrounding the Bohai Sea (i.e. 40 cities) and the Yangtze Delta city system (i.e. 40 cities). They found that, first, in the same economic zone the annual growth rates of cities had nothing to do with their initial sizes; second, city size distribution had not changed much over time; and third, future changes of city size distribution would mainly take place in small cities and they would change slowly. However, whether this research has revealed the general rules of China's city size distribution still needs further empirical studies, due to the short time span, small geographical scopes, and some data adjustment involved in the research.

\footnotetext{
${ }^{10}$ Song, Shunfeng, and Kevin Honglin Zhang. "Urbanisation and City Size Distribution in China." Urban Studies 39, no. 12 (2002): 2317-27, p. 2318.

${ }^{11} \mathrm{Xu}$, Zelai, and Nong Zhu. "Urban Growth Determinants in China." Chinese Economy 41, no. 1 (January-February 2008): 7-35.
} 
To appear in Chinese Economy, No. 6 (2012)

In fact, the case of China, with its large territory, great regional disparity ${ }^{12}$, high population density, rapid economic development, and economic transition from a socialist economy to a market economy, has provided us with a good opportunity to study the size distribution of urban systems. In this research, we will take the Chinese urban system as a whole and study its changing trends of distribution over time. We will compare those trends with findings from cross-country studies so as to identify differences between China and other countries in terms of city size distribution. Our findings might help test the validity of a longterm policy in China, which primarily uses city size as an urban development guideline.

\section{Data and Methods}

To have a wide coverage of Chinese urban system, we use a dataset from 1949, when the Chinese Communist Party (CCP) took over power, to 2008, which is the most recent year for which we can obtain data. Following the existing literature, we measure city size or city scale by the urban or non-agricultural population in each city. Despite the strict household management system (huji guanli) implemented since 1958 in China, a large number of rural workers have migrated to urban areas, especially in recent years, to work in cities for higher wages. Very likely there is a substantial divergence between the number of urban or non-agricultural residents in the statistical year books and the real number of residents who rely on non-agricultural production for a living. However, these un-accounted migrants are not permanent urban residents and many of them only stay in cities for less than six months. Therefore, temporary migrants are not included in our calculation. Also, data from the non-agricultural population has the advantage of availability and continuity when compared with other measures, such as urban territories and cities' administrative boundaries. But we will discuss the impacts on our results brought by the

\footnotetext{
${ }^{12}$ For urbanization and urban-rural inequality, see Lu, Ming, and Zhao Chen, "Urbanization, Urban-Biased Policies, and UrbanRural Inequality in China, 1987-2001." Chinese Economy 39, no. 3 (May-June 2006): 42-63.
} 
To appear in Chinese Economy, No. 6 (2012)

potential measurement bias while presenting our findings.

The Chinese city system is large and complex. It includes three groups of cities, based on their administrative ranks: county-level cities, prefecture-level cities, and centrally-administered municipalities. Along with industrialization, urbanization, and the continuous emergence of new cities, there have been some adjustments of the administrative ranks and divisions of several cities. For instance, a county-level city may be upgraded into a prefecture-level one. A quasiprovincial city may be upgraded to a centrally-administered municipality, such as Chongqing in 1997. Many townships (xiancheng) have also actively pursued upgrading and have been reclassified as cities in the past several decades, since higher administrative ranks give them greater autonomy, more political power, and easier access to resources in China. This fanaticism of administrative upgrading resulted in a steep increase in the total number of cities from 223 in 1980 to 667 in 1999. In the process of upgrading, some existing cities, such as Chongqing, have expanded their territories and others have merged with adjacent cities or combined with surrounding counties (Song and Zhang 2002). Because these adjustments resulted in inconsistency and discontinuity within the urban population data from 1949 to 2008 , we pick three sub-datasets including different numbers of cities with continuous and consistent data and choose to focus more on the recent city distribution trend from 1990 to 2008 . The three subdatasets can help double check the robustness of our findings. The three datasets are 1) a group of 48 randomly selected cities during 1949-2008, using 1949 as the base year. This group includes large, middle, and small cities, without considering cities which newly emerged or have been removed in the recent decades. Results based on this sample give an overview of China's urban growth since 1949. Actually, based on information in hand, these 48 cities are also the only cities whose data of non-agricultural residents is continuous and available every year during this 
To appear in Chinese Economy, No. 6 (2012)

long time period. 2) The top 100 cities during 1990-2008 using 1990 as the base year. 3) The top 211 cities during 1990-2008 using 1990 as the base year. As for adjustments to administrative ranks and divisions, we take those as endogenous changes of city system and, thus, make no statistical adjustment accordingly. All data in this research is collected from two book series, New Chinese Cities 50 Years (1949-1998) (Xinzhongguo chengshi wushi nian) and Chinese Urban Statistical Yearbooks (1999-2009).

We employ several different methods to check different aspects of city size distribution development in China. First, we use time series Gini coefficients to examine the size distribution of Chinese cities. It is a well-known approach measuring income inequality in a society. As reviewed previously, urban economists have largely borrowed this approach to gauge the distribution of different-sized cities. If Chinese cities follow a convergent or divergent growth model, the Gini coefficients are expected to decrease or increase accordingly. On the contrary, if China's city size distribution takes the parallel growth model, the Gini coefficients should stay unchanged over years. Second, we employ a panel unit root test to investigate whether the overtime changes of Chinese urban population distribution follows Gibrat's law. Third, we analyze distribution dynamics to discuss the impact of individual city size distribution on the entire urban system distribution over time. Since the last two methods also require data on other aspects of a city besides population, such as infrastructure, the largest sample that includes all necessary data is the top 211 cities. Therefore, both methods are applied upon this dataset. We will explain the last two methods in greater detail in the following section.

\section{Results and Findings}

In this section, we present our results from the different methods and briefly discuss our findings. In general, we find that China's city size distribution has changed from a convergent growth 
To appear in Chinese Economy, No. 6 (2012)

model to a parallel growth model during the period studied. Detailed findings are presented below.

\section{1) Gini Coefficients of the City Size Distribution in China}

The time series Gini coefficients based on different samples are presented in Figures 1-2.

Figure 1 is based on the 48 cities from 1949 to 2008. In general, we can observe two growth patterns before and after 1978. In the first stage, 1949-1978, the Gini coefficients present an apparent tendency of decline. This means that Chinese city size distribution in this time period grew in a convergent model. Cities became more balanced or even in terms of size. In the second stage, 1978-2008, this decline trend starts to slow down from 1978 and almost disappears from the mid-1990s onwards. Especially during the period of 1996-2008, the Gini coefficients basically fluctuate closely around 0.4 with a relatively large drop in 1998-2003, followed by a quick rebound. This shows that city size distribution had mainly taken an approximately parallel growth model with very limited convergence, and a small and short period of divergence during the second time period. In both time periods — before and after 1978 - there were some changes in city size ranks, especially for those relatively small cities. However, in general this sample of 48 cities reveals a pattern of the evolution of Chinese city size distribution, which had transformed from an apparent convergent to only a slightly convergent growth model (partially with a little divergent growth), and finally to an approximately parallel growth model.

We double check these findings, especially the emerging parallel growth trend of Chinese cities since the 1990s, with datasets from 1990-2008. Figures 2 illustrates the Gini coefficients based on the two samples consisting of the top 100 cities and the top 211 cities between 1990 and 2008 in two lines, respectively. The Gini coefficients of the top 100 cities have maintained between 0.423 and 0.452 during the 19 years in question. And the Gini coefficients of the top 211 
To appear in Chinese Economy, No. 6 (2012)

cities have moved between 0.492 and 0.525 . Both lines show that city size distribution had presented an approximately parallel growth, in general, with a little convergence from 1990 to 1998 and a little divergence from 1998 to 2008, since the Gini coefficients in both lines decrease slightly first before 1998 and then increase slightly later after 1998. Here, it should be noted that the divergence among cities may be underestimated a little because of the exclusion of temporary migrants. Most migrant workers move to large coastal cities for short-term jobs, which could temporarily lead to an even more rapid growth of the urban population in large cities. However, we expect population in large cities return to their normal scale when migrant workers go back to their villages after the short-term employment in urban areas. Also important, the fact that city size distributions based on the same initial year (i.e. 1990) follow the same pattern, regardless of sample sizes in Figures 2, demonstrates that changes of city size distribution are not affected by number of observations.

Based on the above results, we may conjecture about future Chinese city system development. Along with the emergence of new cities, city size distribution will continue to follow parallel growth model if the new city system is used as the initial system. Although in this process there might exist some slight divergent growth, especially if we measure city size by the urban residents (i.e. including temporary migrants) instead of the non-agricultural population, the parallel growth pattern should hold for the long run.

\section{Figure 1-2 Inserted Here}

\section{2) Gibrat's Law and Changes of China's City Size Distribution}

Developed by the French economist Gibrat, Gibrat's law (1931) holds that the size of a firm and its growth rate are independent. This law also applies to city size and growth rate and becomes an important rule. According to Gibrat's Law, although population size differs by cities, 
population growth rates do not rely on city scales. The mechanism causing population growth tends to be universal across cities. If city size and its growth rate are independent of each other, under the condition of limiting distribution, we should be able to find city size distribution consistent with Zipf's law. ${ }^{13}$ In general, the city size distribution characterized by Gibrat's law converges to a limiting distribution, which may be log-normal or power law, depending on more specific assumptions about the stochastic convergence of urban growth.

Several scholars have explored the validity of Gibrat's law of urban growth. Clark and Stabler (1991), utilizing a unit root test, examined the Canadian city size distribution empirically and found that the distribution follows Gibrat's law, as Canadian city size is independent of its growth rate. Sharma (2003) used the same method to examine Indian city system development and found the Indian city system to also be consistent with Gibrat's law. Here we borrow their approach and test whether China's city size distribution also follows Gibrat's law. We employ a panel unit root test.

Let $S_{i t}$ be the size of the $i$ th city during time $t$, then the relation of the $i$ th city's size in time $t-1$ can be represented by equation (1) below:

$$
S_{i}=\xi S_{i-1}, \quad i=1, .2 . N
$$

where $\xi_{i t}$ represents the growth rate of city size from time $t-1$ to $t$. The population growth rate in a city consists of three parts: first, a random component $\varepsilon_{i t}$; second, non-random factors causing city growth; and third, the city size in time $t$. We can write equation (2) as below ${ }^{14}$ :

\footnotetext{
${ }^{13}$ If the city system satisfies Zipf's law, the Zipf coefficient should be 1 . If the Zipf coefficient is smaller than 1 , then city size distribution tends to be convergent. If the Zipf coefficient is larger than 1, then city size distribution tends to be divergent. For more on Zipf's law and Gibrat's law, as well as their application, please refer to Gibrats (1931), Zipf (1941), Rosen and Resnick (1980), Mills and Hamilton (1989), Clark and Stabler (1991), Simon (1995), Krugman (1996), Gabaix (1999), Brakman (2001), and Soo (2005).

${ }^{14}$ For unit root tests, please refer to Dickey, D.A. and W.A. Fuller (1979). "Distribution of the Estimators for Autoregressive Time Series with a Unit Root," Journal of the American Statistical Association, 74, p.427-431. Sargan, J.D. and Alok Bhargava (1983). "Testing residuals from least squares regressions for being generated by the Gaussian random walk," Econometrica, 51,
} 
To appear in Chinese Economy, No. 6 (2012)

$$
\xi_{i t}=\phi_{i t} S^{\delta_{i}}{ }_{i t-1} \prod_{j=1}^{p} \xi^{\beta_{i j}}{ }_{i t-j}\left(1+\varepsilon_{i t}\right)
$$

where $\phi_{i t}$ represents a constant which changes with time and $\delta_{i}$ represents the impacts of the initial city size on urban growth rate during city system development. $\beta_{i j}$ is the impact of previous growth rates on current urban growth rate. $\varepsilon_{i t}$ is the error term. If urban population development follows Gibrat's law, we expect to find that $\delta_{i}=0$, which means that initial city size has nothing to do with growth rate. We take double $\log$ for equation (2), when $\varepsilon_{i t}$ is very small, $\ln \left(1+\varepsilon_{i t}\right) \approx \varepsilon_{i t}$, and we can obtain the unit root equation (3) as below:

$$
\Delta \ln S_{i t}=m_{i t}+\theta_{i} \ln S_{i, t-1}+\sum_{j=1}^{p} \beta_{i j} \Delta \ln S_{i t-j}+\varepsilon_{i t}
$$

where $m_{i t}=\phi_{i t}, \theta_{i}=\delta_{i}-1$. We may check whether equation (3) has a unit root. If a unit root exists, the time series is non-stationary, which means that individual city size is independent of its growth rate and that Chinese city size distribution follows Gibrat's law. On the contrary, if no unit root exists, it means that city size distribution develops evenly over time and initial city size is correlated to its growth rate. The larger a city is, the more slowly it tends to grow. However, when a cross-section dataset has a short time span, equation (3) lacks the validity of a unit root test. Levin, Lin, and Chu (2002) and Im, Pesaran, and Shin (2003) proposed the method of a panel unit root test. According to this method, $H_{0}: \theta_{i}=0, H_{1}: \theta_{i}<0, i=1,2, \ldots N, \theta_{i}=0$, $i=N+1, N+2, \ldots N$. The null hypothesis is that the dataset for an empirical test has a unit root. The alternative hypothesis is that the time series is stationary. This method has been utilized widely. Since our dataset covers a time span from 1990 to 2008, which is not very long, we take

p.153-174. And Bhargava, Alok (1986). "On the theory of testing for unit roots in observed time series," Review of Economic Studies, 53, pp.369-384. 
To appear in Chinese Economy, No. 6 (2012)

the approach of a panel unit root test.

Table 1 lists the panel unit root test results of Chinese city size distribution. Regardless of method, the results all show that Chinese city size distribution has a unit root or that its time series changes have been non-stationary. Therefore, we can conclude that Chinese city size distribution follows Gibrat's law, as in many other countries. Initial city size is independent of growth rate. Urban growth rates are not related to city scales, regardless of city size, large or small.

\section{Table 1 Inserted Here}

\section{3) Distribution Dynamics and Parallel Growth of Chinese City System}

Both Gini coefficients and the Gibrat's law test reveal that Chinese city size distribution, measured by non-agricultural population, has followed a parallel growth model overall. However, is this parallel growth sustainable? Although the entire urban system appears to be growing in a parallel way currently, with new cities emerging, the population distribution is subject to possible change. In fact, in the past several years with urbanization and industrialization, there have been new cities continuously joining in Chinese urban system. However, Gini coefficients are unable to reflect this dynamic of urban system development and unable to answer our question. Thus, we employ the Nonparametric Stochastic Kernel Estimation of Quah (1993) to analyze the dynamic distribution of urban population changes.

Let's assume that the urban population distribution dynamic is a space of a first-order Markov process. The transformation matrix of the Markov process from time $t$ to $t+\tau$ is the conditional distribution function of urban population distribution from time $t$ to $t+\tau$. We can write function (4) as below:

$$
f_{\tau}\left(S_{t+\tau} \mid S_{t}\right)=\frac{f_{t, t+\tau}\left(S_{t+\tau}, S_{t}\right)}{f_{t}\left(S_{t}\right)}
$$


where $S_{t}$ and $S_{t+\tau}$ represent the urban population size in time $t$ and $t+\tau \cdot f\left(S_{t}\right)$ and $f\left(S_{t+\tau}\right)$ are the corresponding urban population distributions. The joint distribution of $f\left(S_{t}\right)$ and $f\left(S_{t+\tau}\right)$ in equation (4) is estimated by a Gaussian kernel with two variables ${ }^{15}$, as shown in equation (5) .

$$
f_{t, t+\tau}\left(S_{t+\tau}, S_{t}\right)=\frac{1}{n h_{1} h_{2}} \sum_{i=1}^{n} k\left(\frac{S_{t}-S_{t i}}{h_{1}}, \frac{S_{t+\tau}-S_{(t+\tau) i}}{h_{2}}\right)
$$

$K$ is the Gaussian kernel function of the two variables. $h_{1}$ and $h_{2}$ are the bandwidth of the Gaussian kernel estimation, which are estimated by cross-validation. $\tau$ is the passage of time from 1990 to 2005 . The relation between equation (5) and the initial city size distribution $f_{t}\left(S_{t}\right)$, and terminal city size distribution $f_{t+\tau}\left(S_{t+\tau}\right)$, is shown in equation (6):

$$
f_{t+\tau}\left(S_{t+\tau}\right)=\int_{S_{t+\tau}} f\left(S_{t+\tau} \mid S_{t}\right) f_{t}\left(S_{t}\right) d S_{t}
$$

As for equation (6), if $t \rightarrow \infty$, according to dynamic transformation function we obtain ergodic density estimation, which shows characteristics of long-term development of city size distribution.

Figure 3 draws the Nonparametric Stochastic Kernel Estimation of city size distribution for 1990-1995 based on equation (6). ${ }^{16}$ Figure 3 is a three-dimensional probability density graph, which illustrates the entire urban population distribution change from 1990 to 1995. If this probability density function distributes along the 45 degree diagonal of X-Y plane from origin ${ }^{17}$, it indicates that the urban population distribution had not changed significantly during the five years, neither towards convergence nor divergence, and that city size distribution had followed a

\footnotetext{
${ }^{15}$ Li, Q. and Racine, J. S. (2007). Nonparametric Econometrics Theory and Practice, Princeton University Press, pp. 24-27.

${ }^{16}$ We choose five-year as a cycle for this test. Thus, the following expansion to 1995-2005 includes two cycles.

${ }^{17}$ In Figure 3, the X axis represents the kernel density distribution of the 1990 urban population; the Y axis represents the kernel density distribution of 1995 urban population; and the $\mathrm{Z}$ axis represents the density distribution of the Gaussian kernel with two variables.
} 
parallel growth. And Figure 3 does show that most probability mass are distributed around the 45 degree diagonal. Therefore distribution dynamics shows that city size distribution grew in a parallel way. Figure 4 further extends the dynamic analysis to the time period of 1995-2005. Based on the three-dimensional distribution, we find that city size distribution had maintained the same pattern from 1995 to 2005 , because all the probability mass of the Nonparametric Stochastic Kernel Estimation is distributed around the principal diagonal of X-Y plane. ${ }^{18}$ This further confirms our finding that urban population distribution has followed a parallel growth model. Figure 5 illustrates the ergodic density curves of equation (6) under limiting distribution. It shows that the ergodic density function almost completely overlaps with the urban population distribution, regardless of the time period, 1990-1995 or 1995-2005. This indicates that under limiting distribution, even considering the potential impacts of new cities' emergence into the entire urban system, city size distribution still maintained a parallel growth model.

\section{Figure 3-5 Inserted Here}

\section{Discussion and Conclusion}

In this research, we employ different methods including time series Gini coefficients, test of Gibrat's law, and distribution dynamics, to examine the over-time evolution of China's city size distribution from 1949 to 2008. Our empirical studies show that Chinese city size distribution shares similarities with many other countries, such as France, Japan, the United States, and India, and grows in a parallel way over the long run. However, some deviation to this model existed in the short run. Therefore, it is still questionable whether parallel growth is a common characteristic across countries. Also, what factors have caused changes in the Chinese city size distribution in different time periods?

\footnotetext{
${ }^{18}$ In Figure 4, the $\mathrm{X}$ axis represents the kernel density distribution of the 1995 urban population; the $\mathrm{Y}$ axis represents the kernel density distribution of 2005 urban population; and the $\mathrm{Z}$ axis represents the density distribution of the Gaussian kernel with two variables.
} 
To appear in Chinese Economy, No. 6 (2012)

A possible explanation is the urban development policies implemented in China since 1949. Chinese urban development has indeed been controlled by state plan, especially before 1978, when the entire economy was dominated by government planning. Moreover, for a long time, Chinese urban planners had held a negative attitude toward developing the city size of large cities. They worried about the potentially large demands for land, insufficient supply of infrastructure and housing, crash of public transportation, and deterioration of the environment possibly caused by over-expansion of the urban population in large cities, or the so called "city disease. $" 19$ Therefore, the growth rate of large cities had been strictly limited in the first few decades under the PRC. The repressive policy towards large cities even continued after the start of economic reform in 1978. In 1980, the central government explicitly embraced the policy of "controlling large cities, developing middle-sized cities reasonably, and actively developing small-sized cities" (kongzhi dachengshi, heli fazhan zhongdeng chengshi, jiji fazhan xiaochengshi). This policy was further promulgated into City Planning Law in 1989, which emphasized controlling the size of large cities again. ${ }^{20}$ Urbanization during the 1980 s and much of the 1990s, to a large degree, was about developing small townships. In this backdrop, from 1949 to 1978 , and even to the 1980 s, Chinese city size distribution experienced a certain degree of convergence, where smaller cities expanded faster than large cities.

However, this repressive policy became gradually ineffective with the deepening of economic reform since the 1980 s. The strict household management system was also loosened over time as urban areas attracted and needed cheap rural workers. Large cities, whose growth was restricted in previous decades, have been developing more and more quickly. Meanwhile,

\footnotetext{
${ }^{19}$ Theories and Practices of Chinese Economic Law (Zhongguo jingji fa lilun yu wushi), http://www.shuku.net:8080/novels/zatan/zgjjfsw/zgjjfsw09-02.html

20 "Which should get priority of development: large cities or small towns?" (Dachengshi yu xiaochengzhen shui youxian fazhan?), from urban planning net (chengshi guihuawang), http://www.guihua.in/zhishicangku/guihuayanjiu/2008-04-15/4724.html
} 
To appear in Chinese Economy, No. 6 (2012)

small cities in the early period of economic reform also maintained a relatively quick growth speed, relying on their previous development momentum and their close proximity to the source of population growth-rural areas. Real change occurred in 1998, when large cities' growth completely surpassed small cities. However, if we also consider the emergence of new cities during economic reform, we may find that the entire city size distribution has not changed so much and it has still followed a parallel growth model.

In general, our research shows that specific government policies directing the development of certain types of cities might be able to affect city size distribution in the short run. But once these policies are removed, city size distribution will return to parallel growth gradually. In the long run, city size distribution also tends to follow the parallel growth model. In countries where the city system is mature and complete, parallel growth results from a relatively even growth rate for all cities, regardless of size. However, in developing countries which undergo rapid urbanization, parallel growth may take a different path. That is, the emergence of a large number of new cities offsets the relatively rapid growth speed of large cities.

Therefore, our empirical research indicates that misperception probably exists in Chinese urban development policies, despite their different concentrations on different-sized cities. In recent years, China has abandoned the old policy of limiting the development of large cities and given more privileges to larger cities in several ways. Along with this adjustment, there are also policy debates on whether development priority should be given to large cities or to middle and small cities. Regardless, it seems that urban development policies have been guided by the mentality of looking for the best city size. However, as pointed out above, city size distribution will only be influenced by government policies temporarily and it has its own development trajectory which is unchangeable by arbitrary policies over the long run. Thus, government needs 
To appear in Chinese Economy, No. 6 (2012)

to shake off the old mentality and make innovative and specific policies tailored for cities with different characteristics, rather than requiring all cities to follow a uniform development model. It is more important to focus on aspects such as urban management rather than city size. There is no need to only develop one type of cities, for instance middle and small cities, while suppressing large cities. In fact, the so-called "city disease" is not necessarily caused by city size, but more by city management. Take the large Japanese city, Tokyo, as an example. It clusters more than 30 million people with one of the highest urban population densities in the world. However, instead of being plagued by city disease, Tokyo owns one of the world's highest productivity, efficiency, and average household income with its superior urban management system. Therefore, focusing more on the internal development within a city is more important than increasing city size externally.

Actually, many internal factors could potentially influence city size distribution. Eaton and Eckstein (1997) and Black and Henderson (1999) point out that city size is determined by endogenous parameters such as the internal productivity and the accumulation of human capital within a city. Besides, city growth depends greatly on the increase of human capital, which in turn relies on an external economy of scale through localization of information and knowledge spillover. In our perspective, human capital might be important for urban growth. However, how important this factor is in the long process of urbanization still needs further research.

\section{References}

[1]Anderson, G. and Ge, Y.(2004).Do Economic Reforms Accelerate Urban Growth the Case of China. Urban Studies 41(11), 2197-210.

[2]Bhargava, Alok (1986). On the Theory of Testing for Unit Roots in Observed Time Series. Review of Economic Studies, 53, 369-384. 
To appear in Chinese Economy, No. 6 (2012)

[3]Black, D.B. and Henderson, J.V. (1999). A theory of urban growth. Journal of Political Economy, 107, 252284.

[4]Brakman,S., Garretsen, H. and Marrewijk, C.V.(2001). An Introduction to Geographical Economics: Trade, Location and Growth, Cambridge University Press.

[5]Chang, L.T.(2009). Factory Girls: From Village to City in a Changing China. Spiegel \& Grau

[6]Clark, S. J.and Stabler, J.C.(1991).Gibrats`s Law and the Growth of Canadian Cities. Urban Studies, 28(4), 635-639.

[7]Davis, J. C. and Henderson, J. V. (2003). Evidence on the political economy of the urbanization process, Journal of Urban Economics, 53, 98-125.

[8]Dickey, D.A. and W.A. Fuller (1979). Distribution of the Estimators for Autoregressive Time Series with a Unit Root. Journal of the American Statistical Association, 74, 427-431.

[9]Ding, C. and Zhao, X. (2011). Assessment of Urban Spatial-Growth Patterns in China during Rapid Urbanization. Chinese Economy, 44, 46-71.

[10]Eaton, J. and Eckstein, Z.(1997). Cities and growth: Theory and evidence from France and Japan. Regional Science and Urban Economics, 27, 443-474.

[11]Gabaix, X.(1999). Zipf's Law for Cities: An Explanation. The Quarterly Journal of Economics, 114, 739767.

[12]Gibrat, R.(1931). Les ine'galite's économiques; applications:aux ine'galite's des richesses, a`la concentration des entreprises, aux populationsdes villes, aux statistiques des familles, etc., d'une loi nouvelle, la loi de l'effet proportionnel. Paris: Librairie du Recueil Sirey.

[13]Guo, C. Z., and Ling, K., et al. (2004). Patterns of Urban Growth: Empirical Evidences from China, Statistical Studies (Tongji yanjiu), 9, 26-32.

[14]Im, K.S., Pesaran,M.H. and Shin,Y.(2003).Testing for Unit Roots in Heterogeneous Panels. Journal of Econometrics, 115, 53-74

[15]Krugman, P.(1996).Confronting the Mystery of Urban Hierarchy. Journal of the Japanese and International Economies, 10, 399-418.

[16]Levin,A., Lin, C.F. and Chu, C.S.J.(2002) Unit Root Tests in Panel Data: Asymptotic and Finite Sample Properties. Journal of Econometrics, 108, 1-24.

[17]Li, Q. and Racine, J. S. (2007). Nonparametric Econometrics Theory and Practice, Princeton University Press

[18] Lu, M., and Chen, Z. (2006). Urbanization, Urban-Biased Policies, and Urban-Rural Inequality in China, 1987-2001. Chinese Economy, 39, 42-63. 
To appear in Chinese Economy, No. 6 (2012)

[19]Madden,C.J.(1956).Some indicators of stability in the growth of cities in the United States. Economic Development and Cultural Change, 4, 236-452.

[20]Mills, E.S. and Hamilton, B.W. (1989).Urban Economics, Pearson Scott Foresman.

[21]Quah, D. (1993). Empirical cross-section dynamics in economic growth. European Economic Review, 37, 426-434.

[22]Rosen, K.T. and Resnick, M. (1980).The size distribution of cities: An examination of the Pareto law and primacy. Journal of Urban Economics, 8, 165-186.

[23]Sargan, J.D. and Alok Bhargava (1983). Testing residuals from least squares regressions for being generated by the Gaussian random walk, Econometrica, 51. 153-174.

[24]Sharma,S.(2003).Persistence and stability in city growth. Journal of Urban Economics, 53, 300-320

[25]Simon, H.A.(1955). On a Class of Skew Distribution Functions. Biometrika, 42, 425-440.

[26]Song, S.F. and Zhang, K.H.L.(2002). Urbanisation and City Size Distribution in China. Urban Studies, 39, $2317-2327$.

[27]Soo, K.T. (2005). Zipf's Law for cities: a cross-country investigation. Regional Science and Urban Economics, 35, 239-263.

[28]Sun, P. S.(1984).Changes of Chinese Urban Population Scale. Acta Geographica Sinica, 39 (4),345-358.

[29]Tiffen, M. (2003). Transition in Sub-Saharan Africa: Agriculture, Urbanization and Income Growth. World Development, 31(8), 1343.

[30]Wang, J.h., Koizumi, A. and Liu, X.(2008). Advancing Sustainable Urban Development in China. Municipal Engineer, 161(1), 3-10.

[31]Wang, F.(2000). Susainable Development of Chinese Urbanization. Beijing: Science Press.

[32]Wang, R.S. and Ye,Y.P.(2004).Eco-City Development in China. Ambio: A Journal of the Human Environment, 33(6), 341-42.

[33]Xu, X.Q.(1982). Evolution and Prejecture of Chinese City-Township system. Journal of Sun Yansen University (Philosphy), 3, 40-49.

[34] Xu, Z. and Zhu, N. (2008) Urban Growth Determinants in China. Chinese Economy, 41(1), 7-35.

[35]Zhou, Y.X. (1986). Review of Changes in Chinese City-Town Rank System and Their Provincial Geographical Type (Woguo chengzhen dengji tixi biandong de huigu jiqi shengqu diyu leixing). Acta Geographica Sinica, 2, 97-111.

[36]Zhou, Y.X.(2003).Urban Geography. Beijing: Commercial Press.

[37]Zhou, Y.B.(2009).Urbanization, rural-urban income gap, and overall income inequality in China - an empirical test of the inverse U hypothesis. China Economics Quarterly, 8(4), 1239-1256 
To appear in Chinese Economy, No. 6 (2012)

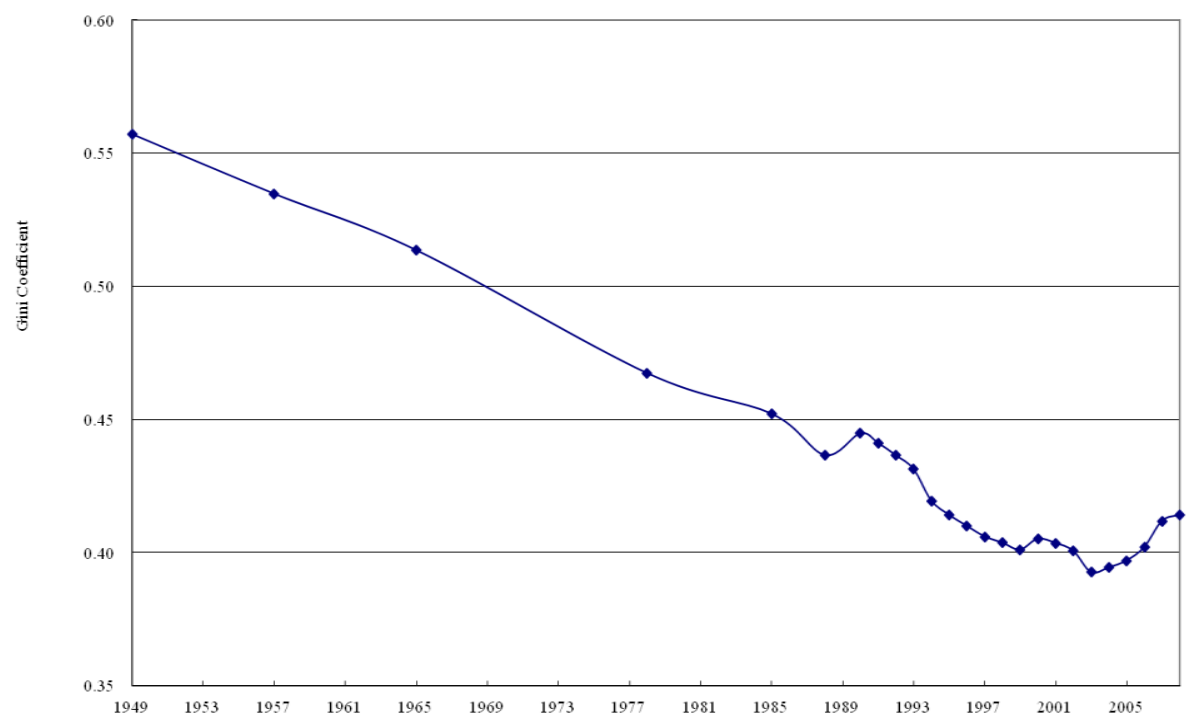

Year

Figure 1 Gini Coefficients of Chinese City Size Distribution based on the 48 Cities, 1949-2008

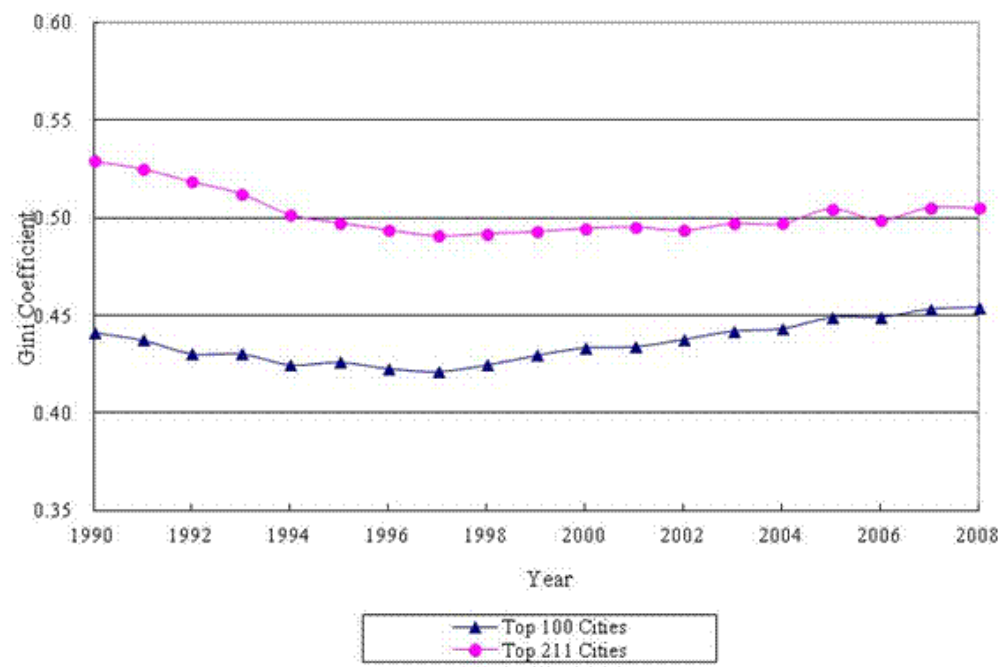

Figure 2 Gini Coefficients of Chinese City Size Distribution based on the Top 100 and 211 Cities, 1990-2008 


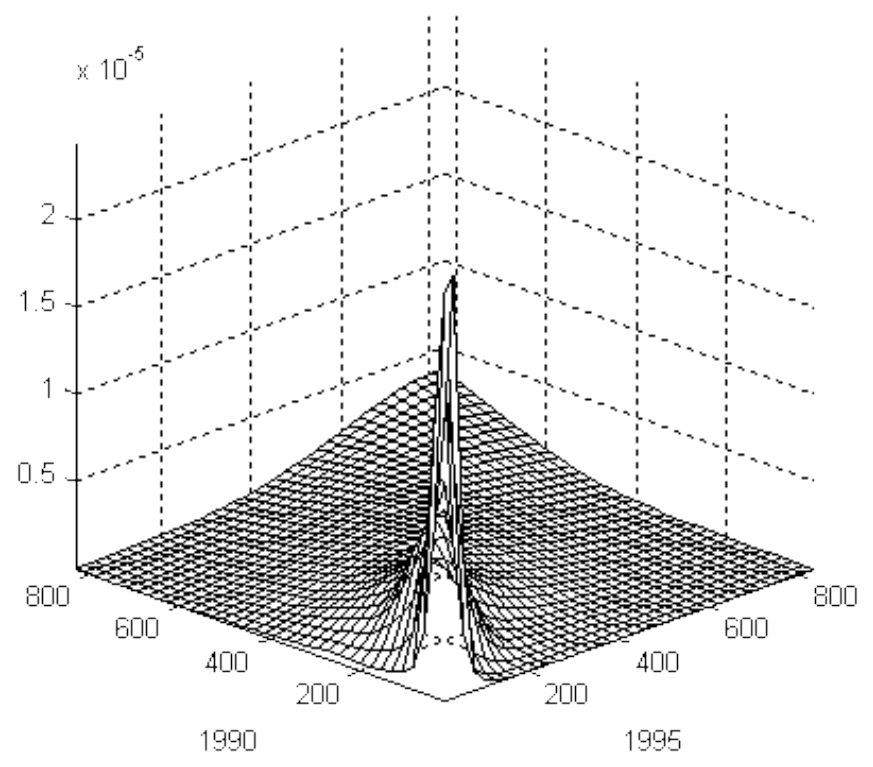

Figure 3 Dynamic Distribution of Chinese Urban Population, 1990-1995

Note: 1. Drawn by Matlab programming of $f\left(S_{t+\tau} \mid S_{t}\right)$.

2. Dataset used: the top 211 cities from 1990-2008 and their data from 1990-1995.

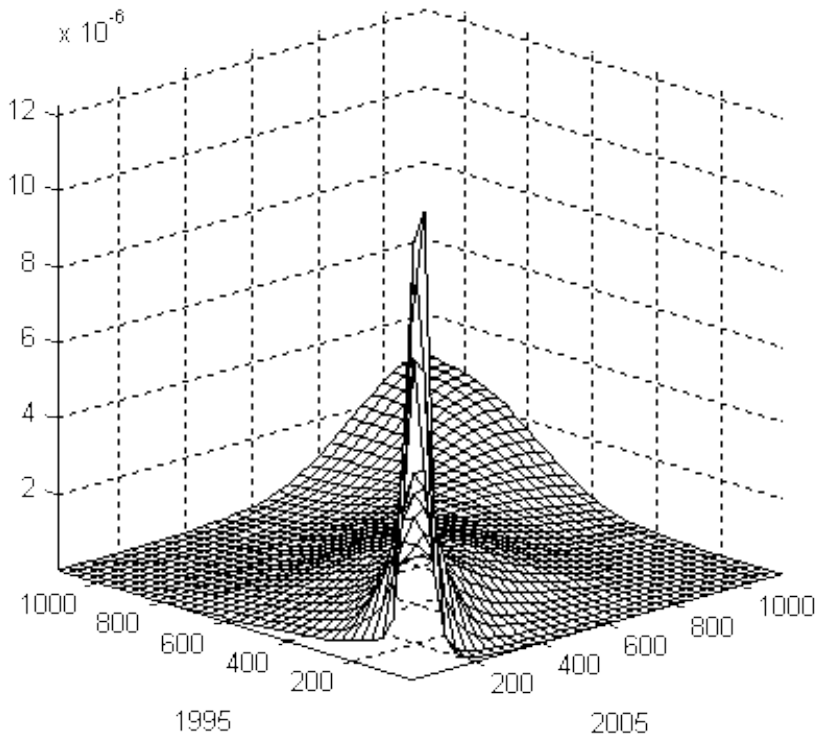

Figure 4 Dynamic Distribution of Chinese Urban Population Scale, 1995-2005

Note: 1. Drawn by Matlab programming of $f\left(S_{t+\tau} \mid S_{t}\right)$.

2. Dataset used: the top 211 cities from 1990-2008 and their data from 1995-2005. 
To appear in Chinese Economy, No. 6 (2012)
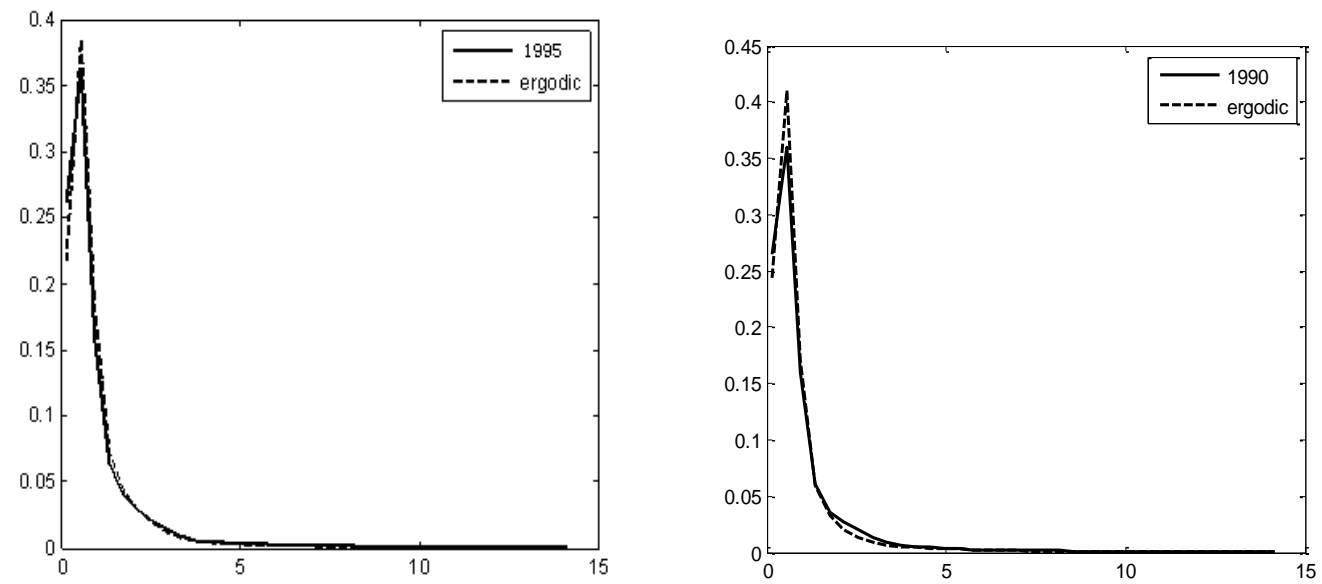

Figure 5 Limiting Distribution of the Evolution of China's City Size Distribution, 1990-1995 and 1995-2005

Note: Drawn by Matlab programming

Table 1 Panel Unit Root Test of Gibrat's Law of Chinese City Size Distribution

\begin{tabular}{l|c|c|c|c}
\hline \hline \multicolumn{1}{c|}{ Method } & Statistics & $\begin{array}{c}\text { Corresponding } \\
\text { Probability }\end{array}$ & $\begin{array}{c}\text { Cross- } \\
\text { section } \\
\text { Obs. }\end{array}$ & $\mathrm{N}$ \\
\hline Levin-Lin-Chu & -70.34 & 0.21 & 211 & 3798 \\
\hline $\begin{array}{l}\text { Im-Pesaran- } \\
\text { Shin }\end{array}$ & -21.23 & 0.423 & 211 & 3798 \\
\hline $\begin{array}{l}\text { ADF-FisherChi- } \\
\text { square }\end{array}$ & 302.75 & 0.127 & 211 & 3798 \\
\hline $\begin{array}{l}\text { PP - Fisher Chi- } \\
\text { square }\end{array}$ & 214.89 & 0.084 & 211 & 3798 \\
\hline \hline
\end{tabular}

Note: Results are based on Stata 10.0 regressions of the top 211 cities from 1990-2008. 